\title{
Lung function, smoking and mortality in a 26-year follow-up of healthy middle-aged
} males

\author{
K. Stavem*,\#, E. Aaser", L. Sandvik+, J.V. Bjørnholt*, G. Erikssen*, \\ E. Thaulow ${ }^{\star}$ and J. Erikssen*
}

ABSTRACT: Lung function has been associated with mortality after adjusting for other risk factors; however, few studies have adjusted for physical fitness and reported separate analyses according to smoking status.

In 1972-1975, spirometry, clinical and physiological parameters were recorded in 1,623 apparently healthy males aged 40-59 yrs. After 26 yrs of follow-up, the current authors investigated the association between baseline lung function and mortality, adjusting for smoking, physical fitness and other potential factors.

By 2000, 615 individuals (38\%) had died, with 308 (50\%) of these deaths from cardiovascular (CV) causes. Forced expiratory volume in one second was a predictor of all-cause mortality (risk ratio (RR) 1.10 per reduction of $10 \%$ ) after adjusting for smoking, physical fitness, age, systolic blood pressure, body mass index and serum cholesterol. The corresponding multivariate RR was $\mathbf{1 . 0 7}$ for CV causes and $\mathbf{1 . 3 4}$ for respiratory death.

In conclusion, in stratified analyses among current and former smokers, forced expiratory volume in one second \% predicted was a strong independent predictor of all-cause mortality and respiratory death among current smokers. Forced expiratory volume in one second \% predicted was not associated with mortality among never-smokers.

KEYWORDS: Cohort study, lung function, mortality, physical fitness, smoking status

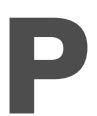

rospective population studies have reported pulmonary function to be an independent predictor of all-cause and cardiovascular (CV) mortality when adjusting for a variety of confounders or known risk factors [1-11]. Poor lung function, measured as forced expiratory volume in one second (FEV1), is also associated with increased mortality from respiratory diseases $[1,3,4,6,8,12,13]$ and malignancies [2, 14-16]. The mechanism for the relationship between lung function and $\mathrm{CV}$ mortality remains largely unexplained. Various mechanisms for the association between lung function and CV mortality have been suggested, such as through systemic inflammation, autonomic dysfunction, physical inactivity, socioeconomic status, residual confounding, or that lung function is an indicator of general health status or unmeasurable environmental or lifestyle influences [13, 17-21].

The impact of lung function on mortality $[22,23]$ and coronary heart disease [24] after adjustment

For editorial comments see page 587 . for self-reported physical activity has been reported, although no studies of mortality have adjusted for objective measures of physical fitness. Few studies also have reported the association between lung function and mortality separately for smoking groups [21].

In this study, the current authors aimed to assess the predictive value of pulmonary function for all-cause, CV and respiratory mortality after adjusting for a number of risk factors, including smoking status and physical fitness. In addition, the present authors intended to assess the association separately in groups with different smoking habits. This study presents data from a population of healthy middle-aged males with follow-up over 26 yrs.

\section{METHODS}

\section{Study subjects}

In 1972, all healthy males aged 40-59 yrs from five companies in Oslo, Norway, were invited to a CV screening survey $(n=2,341)$, and 2,014 $(86 \%)$ consented to participate. The companies included Siemens AS, and four from the public sector

\section{AFFLLIATIONS}

*Medical Dept, Akershus University

Hospital, Lørenskog, and

\#Norwegian Health Services

Research Centre,

"Medical Dept B, Rikshospitalet

University Hospital, and

${ }^{+}$Center for Clinical Research,

Ullevaal University Hospital, Oslo,

Norway.

\section{CORRESPONDENCE}

K. Stavem

Medical Dept

Akershus University Hospital

N0-1478 Lørenskog

Norway

Fax: 4767902125

E-mail: knut.stavem@klinmed.uio.no

Received:

January 212004

Accepted after revision:

December 222004
European Respiratory Journal Print ISSN 0903-1936

Online ISSN 1399-3003 
(Norwegian Postal Services, Norwegian Telecom, Norwegian Customs and Excise, and Norwegian State Railways). The participants had to be free from known or suspected heart disease, drug-treated hypertension, diabetes mellitus, malignancy, advanced pulmonary, renal and liver diseases, and locomotor activity limitation [25].

\section{Examination and measurements}

Between August 1972 and March 1975, the participants underwent an examination programme that included a detailed case history, chest radiograph, measurement of resting heart rate and blood pressure, spirometry, a symptom-limited exercise ECG test, and fasting blood tests [25].

Forced vital capacity (FVC) and FEV1 were measured with a calibrated Bernstein spirometer, using a standardised procedure [25]. After one trial test, FVC and FEV1 values were recorded from two successive maximum expiratory manoeuvres [26], corrected to body temperature and ambient pressure and saturated with water vapour, based on daily room temperature measurements and an assumption of atmospheric pressure of $760 \mathrm{mmHg}$. Originally, only the mean FEV1 and FVC values were recorded. In order to obtain the maximum of the two tests, in 2001, the original spirograms were retrieved and values for both manoeuvres were recorded. Among 1,999 patients with original spirometry recordings, 75 of the records (72 consecutively numbered) had disappeared in storage. Thus, 1,924 spirograms were available for review. In a further analysis, patients with $\leqslant 0.3 \mathrm{~L}$ difference between the two FVC tests $(n=1,623)$ were included [27, 28]. Reference values for maximum values were derived in the total sample using multiple linear regression $(n=1,623)$, as follows:

$\mathrm{FEV}_{1} \mathrm{~L}=-1.419+0.0417 \times$ height in $\mathrm{cm}-0.0429 \times$ age in $\mathrm{yrs}$
$\mathrm{FVC} \mathrm{L}=-4.099+0.0607 \times$ height in $\mathrm{cm}-0.0374 \times$ age in $\mathrm{yrs}$

The symptom-limited exercise test was performed on a calibrated electrically braked bicycle (Elema-Schönander $\mathrm{AB}$, Solna, Sweden). The initial workload was $100 \mathrm{~W}$ $\left(600 \mathrm{kpm} \cdot \mathrm{min}^{-1}\right)$ with increments of $50 \mathrm{~W}(300 \mathrm{kpm})$ every $6 \mathrm{~min}$, continued until exhaustion unless stopped earlier for safety reasons [25]. Physical fitness was defined as total work divided by body weight (in $\mathrm{kJ} \cdot \mathrm{kg}^{-1}$ ).

\section{Identification of deaths}

Mortality data up to December 31, 1999 were obtained from Statistics Norway (Oslo, Norway), coded according to the Eighth and Ninth Revision of the International Classification of Diseases (ICD-8 and ICD-9) [29, 30]. CV mortality consists of (ICD-9 codes in parentheses): ischaemic heart disease (410-414), cerebrovascular disease (430-438), other CV disease (401-404, 420-429, 440-448) and sudden death (798.1). Sudden death was defined as unexpected or unwitnessed death within $24 \mathrm{~h}$ of being seen alive and well, or, if witnessed, within $1 \mathrm{~h}$ of symptom onset. Respiratory mortality consisted of lung cancer (162), pneumonia (480-487), obstructive lung disease (490-496) and other respiratory diseases $(137,163)$. Migration was minimal in this cohort; only two individuals were not available in the registry of Statistics Norway at the end of 1999. All death certificates were reviewed by at least two of the investigators.

\section{Statistical analysis}

The sample was subdivided into FEV1 \% pred quartiles (Q1-Q4) in order to study the differences in CV and all-cause mortality that are related to lung function. Baseline values were compared using the test for trend or Chi-squared test. Mortality curves according to FEV1 \% pred quartile were created plotting separate Cox proportional hazards models, adjusted to age 50 yrs. Cox's proportional hazards regression models were used to assess the association of FEV1 \% pred with mortality after adjustment for established risk factors for $\mathrm{CV}$ death (age, serum cholesterol, systolic blood pressure) and potential confounders (smoking habits, physical fitness, body mass index (BMI)).

Four Cox models were created for the total sample and separate models for never-smokers, previous smokers and current smokers, based on baseline smoking status. The results are presented as relative risks (RR) with $95 \%$ confidence intervals. For FEV1 \% pred, the effect of $10 \%$ reduction was modelled. Physical fitness was used as a continuous variable [31-33], modelling the effect of a change of $0.55 \mathrm{~kJ} \cdot \mathrm{kg}^{-1}$ (1 SD). BMI was modelled as a continuous variable that, in the studied population, contributed to better fitting models than categories based on quartiles.

Smoking status was categorised as never-smokers, former smokers, 1-10 cigarettes per day, and $>10$ cigarettes per day. Smoking status from a follow-up study after $\sim 8$ yrs was available for 1,423 of the 1,623 individuals (88\%) with acceptable spirometry. The exact dates of the events were used for censoring in the models. In the Cox models, smoking status was included as a time-dependent covariate, assuming that changes in smoking status appeared at the midpoint of time between the two assessments. For subjects without follow-up smoking status, unchanged smoking status was assumed.

In stratified analysis according to baseline smoking status, the two classes of smokers were aggregated into current smokers. For current smokers, pack-yrs were calculated using reported smoking volume at the study start as the average volume for the period (midpoint of the intervals 1-5, 6-10, 11-15, 16-20 and 21-25 cigarettes $\cdot$ day $^{-1}$, and 28 cigarettes $\cdot$ day $^{-1}$ for those reporting $>25$ cigarettes $\cdot$ day $^{-1}$ ). In the analysis of respiratory mortality, there were too few events among never-smokers (nine deaths) and former smokers (16 deaths) to justify separate analyses for these groups.

The proportional hazards assumption was checked using plots of the hazard function, log-log of the hazard function, and a test for proportional hazard [34]. A 5\% significance level was chosen, using two-tailed tests.

\section{RESULTS}

Acceptable spirometric recordings, according to the current authors' criteria, were available in 1,623 of the 2,014 apparently healthy males ( $84 \%$ of the 1,924 spirograms reviewed). The sample mean \pm SD age was $49.8 \pm 5.5 \mathrm{yrs}$, and the mean unadjusted FEV1 was $3.50 \pm 0.75 \mathrm{~L}$. Table 1 presents patient characteristics according to the quartiles of FEV1 \% pred (Q1 with the lowest, and Q4 with the highest values for FEV1\% pred). There was an association between FEV1 \% pred with other spirometric indices, physical fitness and smoking history, 
TABLE 1 Baseline subject characteristics according to quartile of relative forced expiratory volume in one second (FEV 1 )

\begin{tabular}{|c|c|c|c|c|c|}
\hline & \multicolumn{4}{|c|}{ Quartile of relative FEV 1} & \multirow[t]{2}{*}{ p-values ${ }^{\#}$} \\
\hline & 1 & 2 & 3 & 4 & \\
\hline FEV $1 \%$ pred cut-off & $\leqslant 89.00$ & $89.01-100.89$ & $100.90-112.16$ & $>112.16$ & \\
\hline Patients n & 405 & 406 & 406 & 406 & \\
\hline FEV $1 \%$ pred & $75.7 \pm 12.8$ & $95.3 \pm 3.3$ & $106.6 \pm 3.2$ & $121.9 \pm 8.9$ & $<0.001$ \\
\hline FVC L & $3.82 \pm 0.73$ & $4.40 \pm 0.61$ & $4.67 \pm 0.57$ & $5.10 \pm 0.71$ & $<0.001$ \\
\hline FEV1/FVC \% & $69.8 \pm 10.5$ & $77.4 \pm 7.2$ & $80.0 \pm 6.5$ & $83.7 \pm 7.3$ & $<0.001$ \\
\hline Age yrs & $50.0 \pm 5.4$ & $49.2 \pm 5.4$ & $50.0 \pm 5.7$ & $50.2 \pm 5.5$ & 0.27 \\
\hline Height $\mathbf{c m}$ & $177 \pm 7$ & $177 \pm 6$ & $176 \pm 6$ & $177 \pm 6$ & 0.65 \\
\hline Body mass index $\mathrm{kg} \cdot \mathrm{m}^{-2}$ & $24.5 \pm 3.1$ & $24.5 \pm 2.7$ & $24.7 \pm 2.7$ & $24.7 \pm 2.5$ & 0.06 \\
\hline Systolic blood pressure $\mathrm{mmHg}$ & $130 \pm 19$ & $130 \pm 18$ & $131 \pm 17$ & $131 \pm 17$ & 0.11 \\
\hline Never-smoker & 17 & 23 & 30 & 29 & \\
\hline Previous smoker & 24 & 32 & 33 & 39 & \\
\hline \multicolumn{6}{|l|}{ Current smoker } \\
\hline 1-10 cigarettes $\cdot$ day $^{-1}$ & 19 & 19 & 12 & 14 & \\
\hline$>10$ cigarettes $\cdot$ day $^{-1}$ & 40 & 27 & 25 & 18 & \\
\hline Current smokers only $n$ & 239 & 184 & 151 & 130 & \\
\hline Number of pack-yrs & $22.2 \pm 11.0$ & $19.8 \pm 10.8$ & $18.9 \pm 9.3$ & $16.7 \pm 9.1$ & $<0.001$ \\
\hline
\end{tabular}

Data are presented as $n$ and mean $\pm S D$, unless otherwise stated. FVC: forced vital capacity. \#: test for trend; ${ }^{\prime}$ : Chi-squared test. $n=1,623$. smoking status and quartile of relative forced expiratory volume in one second (FEV1)

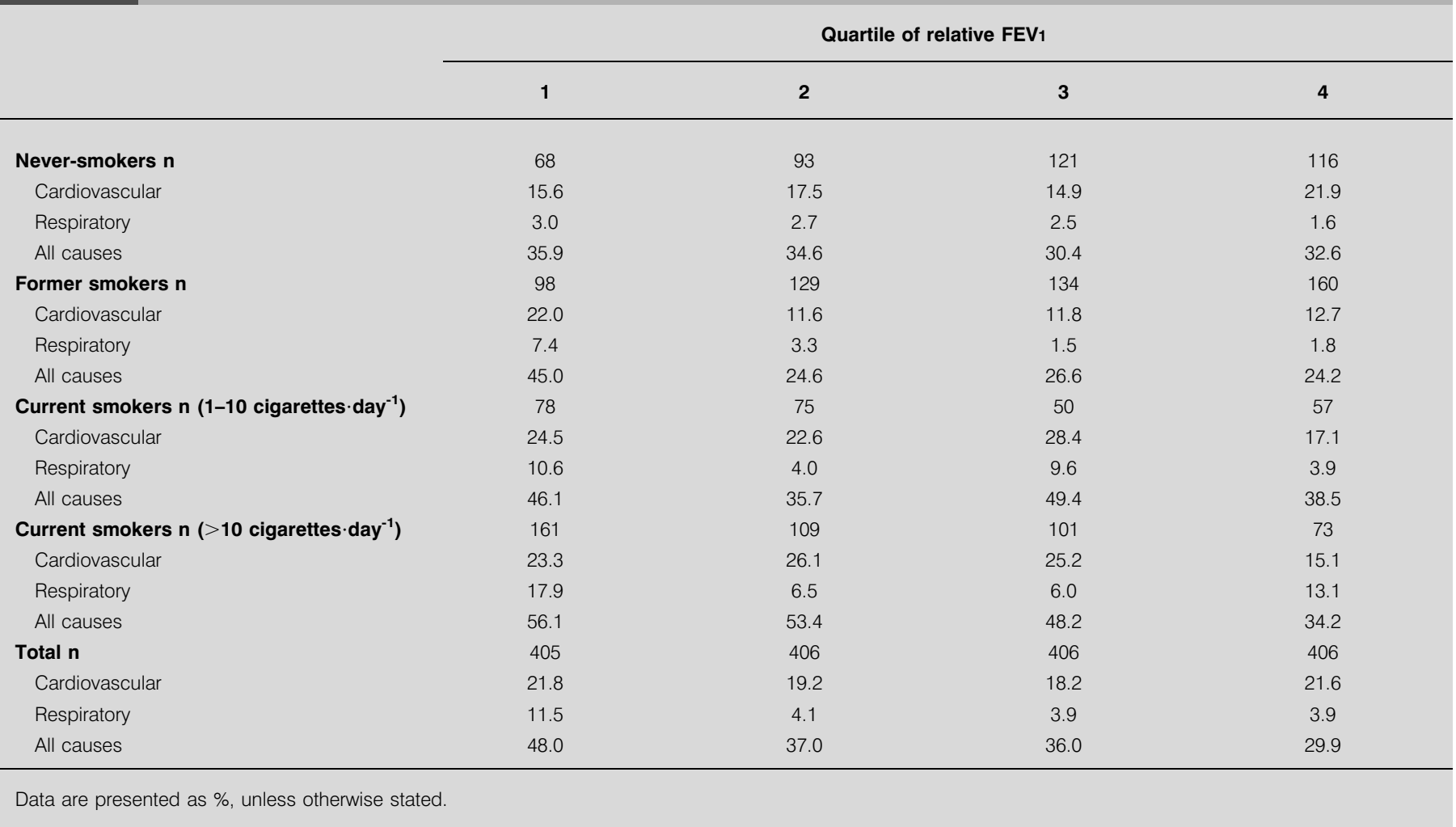




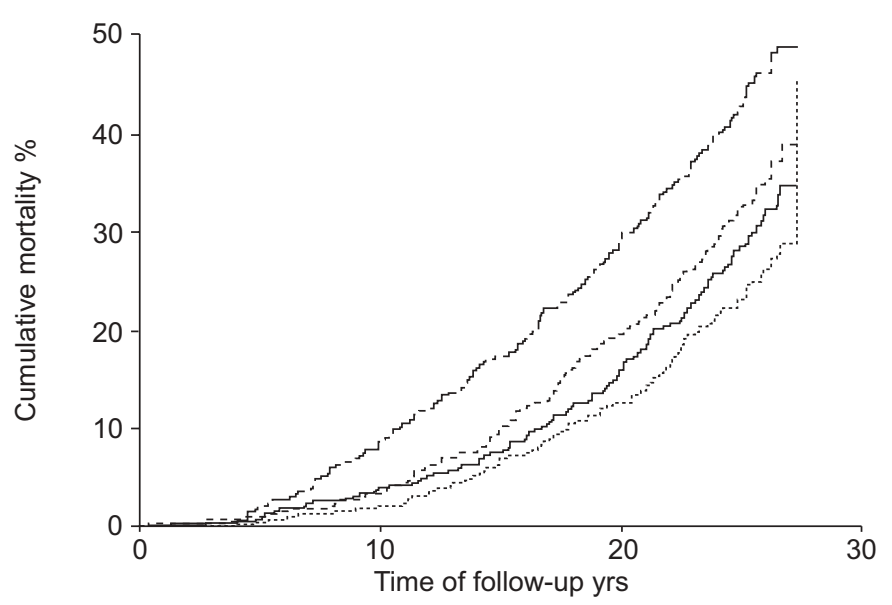

FIGURE 1. Cumulative age-adjusted mortality according to quartile of relative forced expiratory volume in one second among 1,623 males over 26 yrs. Quartile 1 (lowest): $-\cdots-$; quartile $2:----$; quartile $3:-$ - quartile $4: \cdots \cdots \cdots$.

but no difference in age or systolic blood pressure between patients classified according to quartile of FEV1 \% pred.

At the follow-up examination after, on average, 8 yrs $(n=1,423$, $88 \%$ of the cohort), $6 \%$ of never-smokers had started smoking (21 out of 356), 10\% of ex-smokers had started smoking again (47 out of 484 ), and $32 \%$ of the baseline smokers reported that they had quit smoking (185 out of 583).

After an average 26 yrs of follow-up (range 25-27 yrs), a total of 42,262 man-yrs, 615 (38\%) men had died, of whom $308(50 \%)$ had died from $\mathrm{CV}$ diseases. In the total sample, the correlation between FEV1 \% pred and the physical fitness measure was 0.23 ( $\mathrm{p}<0.001$; Pearson's correlation), and was -0.21 between

\begin{tabular}{|c|c|c|c|c|c|}
\hline \multirow{3}{*}{\multicolumn{2}{|c|}{ TABLE 3}} & $\begin{array}{l}\text { death dur } \\
\text { to the for } \\
\left.E V_{1}\right) \% \text { p }\end{array}$ & $\begin{array}{l}\text { ng the } 26 \\
\text { ced expir } \\
\text { edicted }\end{array}$ & $\begin{array}{l}\text {-yr study } \\
\text { atory volu } \\
\text { uartile }\end{array}$ & $\begin{array}{l}\text { period } \\
\text { ne in one }\end{array}$ \\
\hline & & \multicolumn{4}{|c|}{ Quartile of relative FEV 1} \\
\hline & & $1^{\#}$ & $2^{*}$ & $3^{+}$ & $4^{\S}$ \\
\hline \multicolumn{6}{|c|}{ Cardiovascular } \\
\hline Ischaemic | & eart disease & $40(9.9)$ & $40(9.9)$ & $36(8.9)$ & $35(8.6)$ \\
\hline Sudden de & & $28(6.9)$ & $20(4.9)$ & $20(4.9)$ & $17(4.2)$ \\
\hline Cerebrovas & ular disease & $10(2.5)$ & $10(2.5)$ & $8(2.0)$ & $14(3.4)$ \\
\hline Other & & $11(2.7)$ & $6(1.5)$ & $10(2.5)$ & $3(0.7)$ \\
\hline \multicolumn{6}{|l|}{ Respiratory } \\
\hline Lung cance & & $20(4.9)$ & $6(1.5)$ & $7(1.7)$ & $9(2.2)$ \\
\hline Pneumonia & & $10(2.5)$ & $8(2.0)$ & $8(2.0)$ & $6(1.5)$ \\
\hline Obstructive & ung diseases & $15(3.7)$ & $2(0.5)$ & $1(0.2)$ & $2(0.5)$ \\
\hline Other respi & atory & $2(0.5)$ & 0 & 0 & 0 \\
\hline Gastrointest & ial cancer & $18(4.4)$ & $15(3.7)$ & $19(4.7)$ & $12(3.0)$ \\
\hline Other cance & & $14(3.6)$ & $17(4.2)$ & $19(4.7)$ & $16(3.9)$ \\
\hline Miscellaneol & & $21(5.2)$ & $20(4.9)$ & $14(3.4)$ & $9(2.2)$ \\
\hline Unknown & & $7(1.7)$ & $2(0.5)$ & $5(1.2)$ & $3(0.7)$ \\
\hline All causes & & $196(48.4)$ & $146(36.0)$ & $147(36.2)$ & $126(31.0)$ \\
\hline
\end{tabular}

Data are presented as $n(\%) .{ }^{\#}: \mathrm{n}=405 ;{ }^{\bullet}: \mathrm{n}=406{ }^{+}: \mathrm{n}=406{ }^{\S}{ }^{\S}: \mathrm{n}=406$
FEV1 \% pred and smoking history $(\mathrm{p}<0.001$; Spearman's rank correlation). Age-adjusted mortality from all causes and respiratory causes was higher in the lowest quartile of FEV1 $\%$ pred (Q1) compared with the other quartiles. For all-cause mortality in the total sample, there was a decreasing trend in mortality from the lowest to the highest quartile (table 2).

In never-smokers, there was little association between FEV1 \% pred both for $\mathrm{CV}$ and all-cause mortality (table 2). Among former smokers, the mortality was higher for $\mathrm{CV}$, respiratory and all causes in Q1 of FEV1\% pred compared with the other three quartiles (table 2). Smokers presented with a less clear association between the quartile of FEV1 \% pred and mortality. Current smokers had higher mortality rates than current nonsmokers for $\mathrm{CV}$, respiratory and all-cause mortality (table 2).

Age-adjusted cumulative mortality from all causes was highest in the first quartile of relative FEV1, with a decreasing trend in mortality from the lowest to the highest quartile (fig. 1). There was an increased mortality from lung cancer and obstructive lung diseases among those in the lowest quartile of FEV1 \% pred (table 3), but little difference in ischaemic heart disease or cerebrovascular disease between the groups.

In the total sample, Cox regression analysis showed that, after adjusting for age, smoking habits, systolic blood pressure, cholesterol, physical fitness and BMI, the RR of all-cause mortality was $1.10(\mathrm{p}<0.001)$ for a decrease in FEV1 \% pred of $10 \%$ (table 4 ). The increased mortality risk of a decrease in FEV1 \% pred of $10 \%$ was similar for CV mortality (RR 1.10; $p=0.04$ ) and slightly higher for respiratory mortality (RR 1.34; $\mathrm{p}<0.001$ ) after adjusting for the same variables.

Both CV and all-cause mortality increased with smoking, although ex-smokers had a statistically nonsignificantly lower all-cause and cardiovascular mortality than never-smokers. BMI increase was associated with increased CV mortality (table 4).

In the stratified analysis of current smokers, a reduction in FEV $1 \%$ pred of $10 \%$ was associated with an $8 \%$ increase in allcause mortality (RR 1.08; $p=0.007$ ) after adjusting for age, smoking habits (pack-yrs), systolic blood pressure, BMI, serum cholesterol and physical fitness (table 5). There was little association of FEV1 \% pred with CV mortality. Among current smokers, smoking intensity in pack-yrs was only associated with all-cause mortality, but not with CV mortality (table 5). In former smokers, FEV1 \% pred was associated with all-cause mortality (RR 1.18; $\mathrm{p}<0.001)$ and CV mortality (RR 1.17; $\mathrm{p}=0.01$ ) in multivariate analysis (table 5). In never-smokers, FEV1 \% pred was associated with all-cause mortality, but not with CV death, after adjusting for other potential predictors (table 5).

\section{DISCUSSION}

Among apparently healthy middle-aged males, lung function, measured as FEV1 \% pred, predicted all-cause and CV mortality during 26 yrs of follow-up, although more so for all-cause mortality than CV mortality. Low FEV1\% pred predicted independently of age, smoking status, an objective measure of physical fitness, systolic blood pressure, serum cholesterol and BMI. 
TABLE 4 Relative risk (RR) of death\# for a reduction in relative forced expiratory volume in one second (FEV1) of 10\%

\begin{tabular}{|c|c|c|c|c|c|c|}
\hline & \multicolumn{2}{|c|}{ Cardiovascular } & \multicolumn{2}{|c|}{ Respiratory } & \multicolumn{2}{|c|}{ All causes } \\
\hline & RR $(95 \% \mathrm{Cl})$ & p-value & RR $(95 \%$ Cl) & p-value & RR $(95 \%$ Cl) & p-value \\
\hline FEV $1 \%$ pred, decrease of $10 \%$ & $1.07(1.00-1.14)$ & 0.04 & $1.34(1.21-1.49)$ & $<0.001$ & $1.10(1.06-1.15)$ & $<0.001$ \\
\hline $\begin{array}{l}\text { Physical fitness, increase of } \\
0.55 \mathrm{~kJ} \cdot \mathrm{kg}^{-1}(1 \mathrm{sD})\end{array}$ & $0.85(0.73-1.00)$ & 0.05 & $0.71(0.52-0.98)$ & 0.04 & $0.82(0.71-0.89)$ & $<0.001$ \\
\hline Former smoker & $0.83(0.60-1.14)$ & 0.25 & $1.82(0.82-4.02)$ & 0.14 & $0.93(0.74-1.16)$ & 0.51 \\
\hline $1-10$ cigarettes $\cdot$ day $^{-1}$ & $1.74(1.22-2.48)$ & 0.002 & $3.26(1.39-7.67)$ & 0.007 & $1.61(1.23-2.09)$ & $<0.001$ \\
\hline$>10$ cigarettes $\cdot$ day $^{-1}$ & $1.66(1.19-2.31)$ & 0.002 & $6.05(2.82-12.96)$ & $<0.001$ & $1.94(1.54-2.46)$ & $<0.001$ \\
\hline $\begin{array}{l}\text { Serum cholesterol, increase } \\
\text { of } 1 \mathrm{mmol} \cdot \mathrm{L}^{-1}\end{array}$ & $1.18(1.07-1.31)$ & 0.001 & $0.97(0.81-1.17)$ & 0.77 & $1.07(1.00-1.15)$ & 0.06 \\
\hline $\mathrm{BMI}$, increase of $1 \mathrm{~kg} \cdot \mathrm{m}^{-2}$ & $1.05(1.01-1.10)$ & 0.02 & $1.00(0.92-1.08)$ & 0.92 & $1.02(0.99-1.06)$ & 0.17 \\
\hline
\end{tabular}

RR: relative risk; Cl: confidence interval; \% pred: \% predicted; BMI: body mass index. Cox regression analysis was performed with smoking status as a time-dependent covariate. \#: after also adjusting for age and systolic blood pressure. $n=1,623$.

Subgroup analysis indicated an association between low FEV1 $\%$ pred and increased all-cause mortality among both current smokers and previous smokers, but not among nonsmokers. Additionally, low FEV1 \% pred was associated with increased death from respiratory causes among current smokers and with $\mathrm{CV}$ death among previous smokers.

These findings are in agreement with previous reports $[1-9,13]$ and demonstrate increased mortality with decreasing lung function. The association of lung function with CV mortality has been less consistent than all-cause mortality, as has also been observed in several other studies [2, 9, 11, 35]. In the present study, an increase in RR of 1.10 for a decrease of $10 \%$ in FEV1 \% pred was also found, as in the Busselton, Copenhagen and National Health and Nutrition Examination Survey (NHANES)1 Epidemiological Follow-up Study (NHEFS) studies $[4,21,36,37]$, despite the fact that the current authors had adjusted for additional variables, including physical fitness. A

TABLE 5 Relative risk of death\# for a reduction in relative forced expiratory volume in one second (FEV1), stratified after baseline smoking status

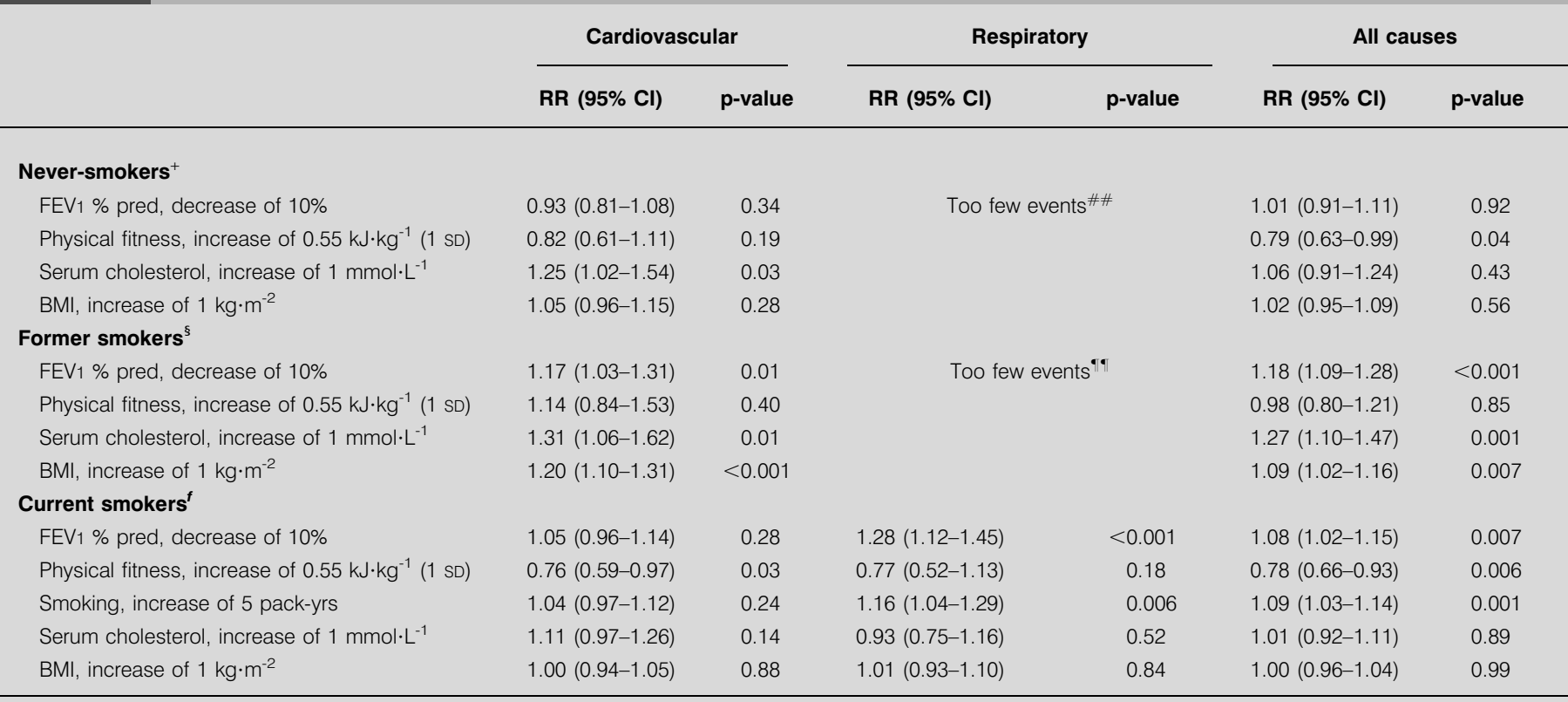

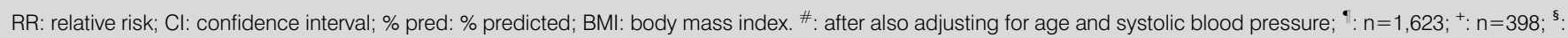
$\mathrm{n}=521 ;{ }^{f}: \mathrm{n}=704 ;{ }^{\# \#} \mathrm{n}=9 ;{ }^{\bullet \bullet}: \mathrm{n}=16$. 
notable finding in the current study was that there was little association between FEV1 \% pred and mortality among never-smokers, also noted in some studies of CV mortality and morbidity [21, 38], but not in all studies [4, 24, 36].

Some of the differences in reported results between studies might be caused by differences in endpoints or methods to adjust for age, height or smoking, or the interaction of smoking with other risk factors [24]. There is no consensus on how to model different aspects of smoking history, including definitions of current and ex-smokers, and how to accommodate the duration and intensity of smoking in statistical models [39]. Moreover, it is difficult to separate the effects of age at initiation, duration of smoking, and time since cessation among ex-smokers because of problems with multicollinearity [39].

Attention has been paid to the association of FEV1 with mortality, because this lung function parameter is more reproducible and less effort dependent than, for example, FVC and peak expiratory flow [40], and, moreover, it is considered to be the lung function variable that best predicts mortality [41]. Most previous studies of the association between lung function and mortality have used FEV1 \% pred as the measure of lung function [13, 21, 41, 42], although some studies have reported similar associations of FVC with CV mortality, for instance in the Framingham study [5], or assessed the association of peak expiratory flow with mortality $[22,23]$.

Relative FEV1 and rate of change in relative FEV1 are associated with reduced self-reported physical activity in the general population $[18,20]$. Self-reported physical activity has also been included as a covariate in longitudinal studies of the association between FEV1 and mortality [22, 23]. However, previous reports of the capacity of relative FEV1 to predict allcause or CV mortality have not adjusted for objective measures of physical fitness, such as those used in this study. In males $<65$ yrs of age, an objective measure of cardiorespiratory fitness was a stronger predictor of coronary events than leisure time physical activity [43]. This negative impact of physical fitness on mortality is well known [31-33]. In the present study, the association of physical fitness with all-cause mortality was more pronounced among current smokers than among former smokers.

The pathogenesis for the association between lung function impairment and increased CV mortality is unknown, although many explanations have been proposed. A low FEV1 \% pred may be a marker of physiological abnormalities that predispose for mortality, and might influence case fatality in various situations. There is a complex interplay between some of the risk factors for $\mathrm{CV}$ mortality, such as BMI, smoking, serum cholesterol and blood pressure. It is well known that hypertension is more common in obese than in lean persons, that smokers on average have a lower BMI than nonsmokers, and that smoking cessation is frequently followed by weight increase [44]. Hence, smoking contributes to CV mortality, but counteracts another CV risk factor, obesity [45]. Some of the risk factors are modifiable through interventions, such as physical fitness, smoking and serum cholesterol. Lung function is not modifiable by training or interventions; however, smoking cessation [46] can influence the rate of decline and, hence, lead to a reduction in mortality [47]. Findings of higher levels of inflammatory markers among persons with lower lung functions indicate that another possible mechanism for increased coronary heart disease could be through a systemic inflammatory response $[17,24]$.

Some limitations of the current study must be mentioned. The sample was an occupational cohort, which might experience favourable survival rates compared with a general population sample because of a possible healthy-worker effect. This could limit the generalisability of the current findings. The cohort consisted only of males. No information about the socioeconomic status of the individuals in the studied sample was available, which is associated with lung function and mortality $[19,48,49]$.

The current authors' data show that smoking habits changed considerably during the first 8 yrs of follow-up. The analyses were adjusted for smoking history after 8 yrs and separate models were created according to baseline smoking status. A relationship between lung function, smoking and mortality might also be nonlinear.

The finding of no association of lung function with all-cause and CV mortality in never-smokers is interesting and lends support to possible residual confounding; however, the sample of never-smokers was too small to fully evaluate this. Reduced lung function might reflect unrecognised cardiac failure, although, with the current authors' inclusion criteria, unrecognised latent heart failure ought to be rare. Moreover, there are clinical, electrocardiographical and radiological follow-up data that do not support that latent heart failure could explain even part of these findings (data not shown). A positive exercise test (ST depression $>0.1 \mathrm{mV}$ on the exercise ECG) was found in $5 \%$ of the subjects, but this finding was also unrelated to low FEV1 $\%$ pred. Hence, it is unlikely that latent heart failure or coronary ischaemia at rest was related to low $\mathrm{FEV}_{1} \%$ pred.

In conclusion, in the present 26-yr prospective follow-up study, it has been shown that forced expiratory volume in one second \% predicted was an independent predictor of all-cause, respiratory and cardiovascular mortality after adjusting for smoking history, physical fitness and well-established risk factors. However, there was little association of forced expiratory volume in one second \% predicted with cardiovascular and all-cause mortality among nonsmokers.

\section{REFERENCES}

1 Higgins MW, Keller JB. Predictors of mortality in the adult population of Tecumseh. Arch Environ Health 1970; 21: 418-424.

2 Krzyzanowski M, Wysocki M. The relation of thirteen-year mortality to ventilatory impairment and other respiratory symptoms: the Cracow Study. Int J Epidemiol 1986; 15: 56-64.

3 Beaty TH, Cohen BH, Newill CA, Menkes HA, Diamond EL, Chen CJ. Impaired pulmonary function as a risk factor for mortality. Am J Epidemiol 1982; 116: 102-113.

4 Bang KM, Gergen PJ, Kramer R, Cohen B. The effect of pulmonary impairment on all-cause mortality in a national cohort. Chest 1993; 103: 536-540. 
5 Kannel WB, Hubert H, Lew EA. Vital capacity as a predictor of cardiovascular disease: the Framingham study. Am Heart J 1983; 105: 311-315.

6 Ebi-Kryston KL. Respiratory symptoms and pulmonary function as predictors of 10-year mortality from respiratory disease, cardiovascular disease, and all causes in the Whitehall Study. J Clin Epidemiol 1988; 41: 251-260.

7 Lange P, Nyboe J, Jensen G, Schnohr P, Appleyard M. Ventilatory function impairment and risk of cardiovascular death and of fatal or non-fatal myocardial infarction. Eur Respir J 1991; 4: 1080-1087.

8 Tockman MS, Comstock GW. Respiratory risk factors and mortality: longitudinal studies in Washington County, Maryland. Am Rev Respir Dis 1989; 140: S56-S63.

9 Cullen K, Stenhouse NS, Wearne KL, Welborn TA. Multiple regression analysis of risk factors for cardiovascular disease and cancer mortality in Busselton, Western Australia: 13-year study. J Chronic Dis 1983; 36: 371-377.

10 Cook NR, Hebert PR, Satterfield S, Taylor JO, Buring JE, Hennekens $\mathrm{CH}$. Height, lung function, and mortality from cardiovascular disease among the elderly. Am J Epidemiol 1994; 139: 1066-1076.

11 Schunemann HJ, Dorn J, Grant BJ, Winkelstein WJ, Trevisan M. Pulmonary function is a long-term predictor of mortality in the general population: 29-year follow-up of the Buffalo Health Study. Chest 2000; 118: 656-664.

12 Peto R, Speizer FE, Cochrane AL, et al. The relevance in adults of air-flow obstruction, but not of mucus hypersecretion, to mortality from chronic lung disease. Results from 20 years of prospective observation. Am Rev Respir Dis 1983; 128: 491-500.

13 Hole DJ, Watt GC, Davey-Smith G, Hart CL, Gillis CR, Hawthorne VM. Impaired lung function and mortality risk in men and women: findings from the Renfrew and Paisley prospective population study. BMJ 1996; 313: 711-715.

14 Tockman MS, Anthonisen NR, Wright EC, Donithan MG. Airways obstruction and the risk for lung cancer. Ann Intern Med 1987; 106: 512-518.

15 Van den Eeden SK, Friedman GD. Forced expiratory volume (1 second) and lung cancer incidence and mortality. Epidemiology 1992; 3: 253-257.

16 Lange P, Nyboe J, Appleyard M, Jensen G, Schnohr P. Ventilatory function and chronic mucus hypersecretion as predictors of death from lung cancer. Am Rev Respir Dis 1990; 141: 613-617.

17 Engstrom G, Lind P, Hedblad B, et al. Lung function and cardiovascular risk: relationship with inflammation-sensitive plasma proteins. Circulation 2002; 106: 2555-2560.

18 Jakes RW, Day NE, Patel B, et al. Physical inactivity is associated with lower forced expiratory volume in 1 second: European Prospective Investigation into CancerNorfolk Prospective Population Study. Am J Epidemiol 2002; 156: 139-147.

19 Blane D, Hart CL, Smith GD, Gillis CR, Hole DJ, Hawthorne VM. Association of cardiovascular disease risk factors with socioeconomic position during childhood and during adulthood. BMJ 1996; 313: 1434-1438.

20 Sin DD, Jones RL, Mannino DM, Paul Man SF. Forced expiratory volume in 1 second and physical activity in the general population. Am J Med 2004; 117: 270-273.
21 Knuiman MW, James AL, Divitini ML, Ryan G, Bartholomew HC, Musk AW. Lung function, respiratory symptoms, and mortality: results from the Busselton Health Study. Ann Epidemiol 1999; 9: 297-306.

22 Persson C, Bengtsson C, Lapidus L, Rybo E, Thiringer G, Wedel H. Peak expiratory flow and risk of cardiovascular disease and death. A 12-year follow-up of participants in the population study of women in Gothenburg, Sweden. Am J Epidemiol 1986; 124: 942-948.

23 Cook NR, Evans DA, Scherr PA, Speizer FE, Taylor JO, Hennekens $\mathrm{CH}$. Peak expiratory flow rate and 5-year mortality in an elderly population. Am J Epidemiol 1991; 133: 784-794.

24 Schroeder EB, Welch VL, Couper D, et al. Lung function and incident coronary heart disease: the Atherosclerosis Risk in Communities Study. Am J Epidemiol 2003; 158: 1171-1181.

25 Erikssen J, Enger SC. Smoking, lung function, physical performance and latent coronary heart disease in presumably healthy middle-aged men. Acta Med Scand 1978; 203: 509-516.

26 Rose GA, Blackburn H. Cardiovascular survey methods. Geneva, World Health Organization, 1968.

27 Quanjer PH, Tammeling GJ. Summary of recommendations. Bull Eur Physiopathol Respir 1983; 19: Suppl. 5, 7-10.

28 Gulsvik A, Tosteson T, Bakke P, Humerfelt S, Weiss ST, Speizer FE. Expiratory and inspiratory forced vital capacity and one-second forced volume in asymptomatic neversmokers in Norway. Clin Physiol 2001; 21: 648-660.

29 World Health Organization. International classification of diseases, ninth revision. Vol. 1. Geneva, World Health Organization, 1977.

30 World Health Organization. Manual of the international statistical classification of diseases, injuries and causes of death: eighth revision. Geneva, World Health Organization, 1967.

31 Blair SN, Kampert JB, Kohl HW 3rd, et al. Influences of cardiorespiratory fitness and other precursors on cardiovascular disease and all-cause mortality in men and women. JAMA 1996; 276: 205-210.

32 Sandvik L, Erikssen J, Thaulow E, Erikssen G, Mundal R, Rodahl K. Physical fitness as a predictor of mortality among healthy, middle-aged Norwegian men. $N$ Engl $J$ Med 1993; 328: 533-537.

33 Laukkanen JA, Lakka TA, Rauramaa $\mathrm{R}$, et al. Cardiovascular fitness as a predictor of mortality in men. Arch Intern Med 2001; 161: 825-831.

34 Grambsch PM, Therneau TM. Proportional hazards tests and diagnostics based on weighted residuals. Biometrics 1994; 81: 515-526.

35 Wannamethee SG, Shaper AG, Ebrahim S. Respiratory function and risk of stroke. Stroke 1995; 26: 2004-2010.

36 Lange P, Nyboe J, Appleyard M, Jensen G, Schnohr P. Spirometric findings and mortality in never-smokers. J Clin Epidemiol 1990; 43: 867-873.

37 Neas LM, Schwartz J. Pulmonary function levels as predictors of mortality in a national sample of US adults. Am J Epidemiol 1998; 147: 1011-1018.

38 Curb JD, Marcus EB, Reed DM, MacLean C, Yano K. Smoking, pulmonary function, and mortality. Ann Epidemiol 1990; 1: 25-32. 
39 Leffondre K, Abrahamowicz M, Siemiatycki J, Rachet B. Modeling smoking history: a comparison of different approaches. Am J Epidemiol 2002; 156: 813-823.

40 Higgins M, Keller JB, Wagenknecht LE, et al. Pulmonary function and cardiovascular risk factor relationships in black and in white young men and women. The CARDIA Study. Chest 1991; 99: 315-322.

41 Olofson J, Skoogh BE, Bake B, Svardsudd K. Mortality related to smoking habits, respiratory symptoms and lung function. Eur J Respir Dis 1987; 71: 69-76.

42 Thomason MJ, Strachan DP. Which spirometric indices best predict subsequent death from chronic obstructive pulmonary disease? Thorax 2000; 55: 785-788.

43 Talbot LA, Morrell CH, Metter EJ, Fleg JL. Comparison of cardiorespiratory fitness versus leisure time physical activity as predictors of coronary events in men aged $\leqslant 65$ years and $>65$ years. Am J Cardiol 2002; 89: 11871192.

44 Williamson DF, Madans J, Anda RF, Kleinman JC, Giovino GA, Byers T. Smoking cessation and severity of weight gain in a national cohort. N Engl J Med 1991; 324: 739-745.
45 Neaton JD, Blackburn H, Jacobs D, et al. Serum cholesterol level and mortality findings for men screened in the Multiple Risk Factor Intervention Trial. Multiple Risk Factor Intervention Trial Research Group. Arch Intern Med 1992; 152: 1490-1500.

46 Sandvik L, Erikssen G, Thaulow E. Long term effects of smoking on physical fitness and lung function: a longitudinal study of 1393 middle aged Norwegian men for seven years. BMJ 1995; 311: 715-718.

47 Pelkonen M, Notkola IL, Tukiainen $H$, Tervahauta $M$, Tuomilehto J, Nissinen A. Smoking cessation, decline in pulmonary function and total mortality: a 30 year follow up study among the Finnish cohorts of the Seven Countries Study. Thorax 2001; 56: 703-707.

48 Smith GD, Hart C, Watt G, Hole D, Hawthorne V. Individual social class, area-based deprivation, cardiovascular disease risk factors, and mortality: the Renfrew and Paisley Study. J Epidemiol Community Health 1998; 52: 399-405.

49 Shohaimi S, Welch A, Bingham S, et al. Area deprivation predicts lung function independently of education and social class. Eur Respir J 2004; 24: 157-161. 